\title{
A Origem (Ursprung) como alvo e o método interpretativo de Walter Benjamin
}

Anna Luiza Coli

UFMG

Resumo: O presente artigo tem por objetivo a análise do método interpretativo proposto por Walter Benjamin no prefácio à obra Origem do drama barroco alemão sob a perspectiva do conceito de Origem (Ursprung) e de sua importância central na compreensão do pensamento sobre a história, presente no texto tardio intitulado "Sobre o conceito da história". A conexão entre a obra sobre o drama trágico do século XVII e o estudo sobre a história consiste na elucidação do conceito de Origem como categoria sobretudo estrutural, em detrimento da leitura que a compreende a partir de um ponto de vista genético, como uma categoria meramente histórica e arcaizante.

Palavras-Chave: Origem, método interpretativo, história.

\section{Arqueologias}

"Quem pretende se aproximar do próprio passado soterrado", escreve Walter Benjamin em um fragmento de seus ensaios literários, "deve agir como um homem que escava. Antes de tudo, não deve temer voltar sempre ao mesmo fato, espalhá-lo como se espalha a terra, revolvê-lo como se revolve o solo. Pois 'fatos' nada são além de camadas que apenas à exploração mais cuidadosa entregam aquilo que recompensa a escavação." A imagem da escavação intermitente, paciente, da atenção exaltada ao objeto e da pormenorização de seus elementos: essa é a efígie da atividade filosófica, tal como esboçada por Benjamin no prefácio ao livro sobre o drama barroco do século XVII. ${ }^{2}$ Representar a verdade que adormece nos objetos, restaurar-lhes a dimensão expressiva e significativa: esse é o propósito de seu método.

O presente artigo tem como objetivo analisar o método interpretativo apresentado no "Prefácio" em sua conexão necessária com a reflexão acerca da história, tendo como ponto de referência a elucidação do conceito de Origem (Ursprung), não apenas como uma categoria histórica, mas como uma categoria de agudo apelo 
estrutural. O primeiro passo é dado no sentido de contextualizar a discussão metodológica e seus interlocutores. Em seguida pretendo explicitar a distinção conceitual entre saber e verdade, como o primeiro passo para a abordagem do método propriamente dito. O último passo consiste na análise do conceito de origem e das conseqüências de uma interpretação que privilegia seu caráter estrutural, em detrimento da leitura canônica que a entende como uma categoria essencialmente histórica, arcaizante.

\section{Cuidado: Atalhos!}

"Método é caminho indireto, é desvio." ${ }^{3} \mathrm{O}$ método interpretativo se apresenta no "Prefácio" epistemológico-crítico como uma instância preliminar que estabelece as diretrizes do acesso à verdade. Até aqui nada de novo. A discussão acerca dos métodos científicos e sua legitimidade roubaram a cena filosófica no período de transição entre os séculos XIX e XX. De maneira até mesmo irônica, entretanto, Benjamin desenvolve um "percurso metodológico" que provocativamente se apresenta como um não-método: é desvio, intermitência, "discurso em curto circuito que a meio caminho interrompe a si mesmo a fim de renovar contato com seus objetos". ${ }^{4}$

A provocação tem alvo preciso: de um lado os positivistas e seus principais representantes exaltavam os fatos e a realidade empírica como o ponto seguro do conhecimento verdadeiro acerca do mundo. De outro, os neokantianos - mais especificamente, os teóricos da escola de Marburg - buscavam nas categorias a priori do Entendimento os preceitos da legitimação do conhecimento empírico. De um lado, temos o que Benjamin entende como a crença em uma "facticidade pura", que postula a existência de um experimentum crucis capaz de decidir a validade de uma teoria científica, e com ela a legitimidade do conhecimento; de outro uma "consciência pura", que fundamenta o real a partir de um princípio explicativo transcendental e estático. De um lado a exaltação unilateral e extrema do objeto; de outro, a do sujeito.

$\mathrm{O}$ esforço de delimitar um método [meta (o que está para além) hodos (caminho)] como via direta de acesso ao conhecimento legítimo, segundo o diagnóstico de Benjamin, "impôs-se em todas as épocas que tiveram consciência do Ser indefinível da verdade". 5 Entretanto, no instante em que o exercício filosófico volta-se a uma tentativa de fundamentação do conhecimento, seja no empírico puro, seja numa consciência transcendental, a filosofia é destituída de seu lugar de "representação da 
verdade", 6 e passa a funcionar como uma espécie de propedêutica. Seu papel limita-se, assim, a buscar as condições e pressupostos cognitivos sobre os quais devem se basear o método, não sendo ela própria o caminho da verdade.

"Se a filosofia quiser permanecer fiel à lei de sua forma, como representação da verdade e não como guia para o conhecimento, deve-se atribuir importância ao exercício dessa forma, e não à sua antecipação como sistema."7 O exercício da representação da verdade: esse é o sentido de um método que revolve impetuosamente seus objetos, que os percorre com rigor até que seus elementos concretos, numeráveis, desdobrem-se na representação daquilo que neles há de indizível e de inapropriável: sua verdade. "Benjamin entende que o método não procura comunicar essencialmente pela enunciação", 8 pois a verdade que emana da demorada contemplação dos objetos é ela mesma essencialmente contemplativa, e não cativa da apreensão categorial. Afinal, o que é a verdade? "Não será isto aquilo que [em um poema] se reconhece em geral como o inapreensível, o misterioso, o 'poético'? Aquilo que o tradutor só pode restituir ao tornar-se, ele mesmo, um poeta?". 9

\section{A nova história da Bela Adormecida}

Se a verdade é o conteúdo inefável e imagético proporcionado pela contemplação do objeto, como é o caso que podemos comunicar ou mesmo detalhar conceitualmente esse mesmo objeto? Para resolver esse impasse, Benjamin reafirma a diferença entre saber e verdade, não apenas enquanto atividades cognitivas distintas, mas principalmente enquanto atividades cognitivas distintas que atuam sobre objetos distintos. Trocando em miúdos, Benjamin defende a idéia de que o objeto do saber não coincide com o objeto da verdade, a despeito do fato de que ambos se refiram a um único ente. "A verdade, presente no bailado das idéias representadas, esquiva-se a qualquer tipo de projeção do reino do saber. O saber é posse."10

O saber não preexiste ao seu objeto, e existe somente na medida em que é apropriado por uma consciência. Pode-se dizer que o saber é a parcela essencialmente apreensível e comunicável de nossa atividade cognitiva. Ele é o signo do trato imediato com o objeto: é seu conteúdo "econômico"," unilateral, desatento às suas particularidades enquanto objeto único, "bruto". ${ }^{2}$ É a máxima de uma atividade intelectiva desatenta, descuidada, que busca no real e em seus objetos a identificação extrema, a síntese exagerada, a redução de todo o conjunto de fenômenos empíricos a 
uma meia dúzia de princípios racionalmente computáveis. A sistematização que parte do objeto de saber prescreve uma aplicação arbitrária a todo e qualquer objeto, um fenômeno histórico ou social ou mesmo deduções de leis naturais. Essa indistinção, muito cara às pretensões universalistas de algumas correntes cientificistas, não é senão um esquecimento, um abandono do objeto em prol da forçosa conformação do real aos limites da consciência.

A verdade, ao contrário, escapa a qualquer tentativa de captura, e o esforço intelectivo persecutório a aniquila por completo. Sua manifestação, quando exaurido o conteúdo material dos objetos, "pode ser caracterizada metaforicamente como um incêndio, no qual o invólucro do objeto, ao penetrar na esfera das idéias, consome-se em chamas, uma destruição, pelo fogo, da obra, durante a qual sua forma atinge o ponto mais alto de sua intensidade luminosa." ${ }^{13}$ A compreensão do problema da verdade exige, no entanto, maior familiaridade com as etapas do método epistemológico propriamente dito.

"Eu gostaria de contar, por uma segunda vez, a história da Bela Adormecida". ${ }^{14}$ Assim começa o irônico prefácio no qual Benjamin apresenta suas considerações de caráter epistemológico sob o aspecto de uma releitura da fábula infantil. Na narrativa, a princesa desfeita em magia um belo dia acorda de seu leito. Mas não é o beijo de seu príncipe que a desperta, e sim a sonora bofetada com que seu cozinheiro desmaia o suposto herói. A verdade é a linda criança que adormece no interior dos objetos. $\mathrm{O}$ príncipe abastado aparece como o vilão que "enfeitado com o deslumbrante equipamento científico", ${ }^{15}$ deseja apossar-se da bela princesa. O cozinheiro é a figura que encarna o papel do método, e faz despertar a verdade sem sequer tocá-la, mantendoa protegida das garras aniquiladoras da ciência.

\section{As constelações e seu segredo}

O método, que para o saber é uma via para a aquisição do objeto (mesmo que através da sua produção na consciência) é para a verdade representação de si mesma e portanto, como forma, dado juntamente com ela. Essa forma não é inerente a uma estrutura da consciência, como é o caso da metodologia do saber, mas a um Ser. ${ }^{16}$

Desse ponto de vista, saber e verdade aparecem não apenas como atividades distintas, mas até mesmo contrárias: "Benjamin considera que seu conteúdo de 
conhecimento [i.e., conteúdo da verdade, e não do saber] será tanto maior quanto mais o que pretendiam enunciar estiver destruído. Só então seu tônus de verdade pode manifestar-se." ${ }^{" 17}$ O saber, como fruto do contato descuidado com o objeto, é a apreensão que o considera como um "todo" orgânico. Entretanto, esse suposto "todo" é compreendido pelo método benjaminiano como uma fraude, uma apreensão parcial e econômica que tem em vista uma exigência metodológica de invariabilidade e ordenação. O problema é que o imobilismo da compreensão e conceitualização do objeto contradizem a nossa experiência ordinária. Não temos a experiência de um pedaço de cera que se mantém sempre o mesmo, mas que se deixa modelar, que amolece na proximidade do fogo e que é passível de outras tantas modificações. ${ }^{18}$ São estes objetos fenômenos distintos, ou não nos é dado conhecê-lo em sua essência? Benjamin responde que, pelo contrário, é esse tipo de fragmentação significativa, de diferenciação fomentada no seio de uma identidade estabelecida o que propriamente caracteriza os objetos. O objeto apreendido pelo saber é uma espécie de síntese, de equacionamento dessas múltiplas facetas sob uma carapaça de imutabilidade, de pura identidade.

A verdade como "morte da intenção", ${ }^{19}$ como impossibilidade de enunciação, cativa apenas do esforço contemplativo, é o resultado de um processo reflexivo que atua fragmentando os objetos em seus diversos elementos constituintes e reagrupando-os sob diferentes perspectivas, até extrair deles todo o potencial significativo encoberto por sua aparente unicidade de acepção. Daí a idéia de que o método deve partir da mutilação de seus objetos (ou bem da queima de seu invólucro material) para restaurar-lhes a verdade: “o conteúdo de verdade só pode ser captado pela mais exata das imersões nos pormenores do conteúdo material". ${ }^{20}$

O método que tem como diretiva mimetizar a estrutura do objeto analisado e não a da consciência analisadora deve, portanto, apresentar-se como digressão, como afastamento-aproximação que escava e fragmenta seus objetos. A cada movimento retrógrado da reflexão, novas facetas e significações vão surgindo e se sobrepondo, de modo que o objeto aparentemente unificado à percepção imediata, revela-se como um mosaico de elementos, como um ser que pela mediação da reflexão aparece como essencialmente fragmentado.

O fenômeno assim implodido pela atividade metodológica é reunido sob as idéias, que conferem uma nova organização a esse emaranhado de elementos. $\mathrm{O}$ termo “idéia" é aqui compreendido, na esteira da teoria platônica das Idéias, como uma 
instância resguardada da corrupção e do vir-a-ser, e que em função dessa permanência "salva" os fenômenos da mera efemeridade. Contrariamente a Platão, no entanto, "idéia" aqui não é a elevação numênica dos elementos universalizáveis do fenômeno, mas sua reorganização concreta. Nisso reside sua capacidade de representar a verdade neles encerrada. Longe das idéias, a verdade das coisas estaria condenada à morte e à dispersão, inaptas à formação de uma unidade significativa, e por isso sujeitas à dispersão no pensamento abstrato, que aniquila toda e qualquer particularidade. Da mesma forma, longe dos fenômenos, as idéias não passariam de elementos abstratos e vazios.

"As idéias se relacionam com os fenômenos como as constelações se relacionam com as estrelas". ${ }^{21}$ Idéia que representa a verdade é aquela que acolhe os elementos de um fenômeno particular e efêmero e, ao dispô-los de maneira fragmentária, como uma espécie de constelação, faz aparecer a verdade neles adormecida. Esse é o nobre segredo encerrado nos recônditos materiais de cada constelação de idéias.

\section{“Origem é o Alvo" 22}

A Origem aparece no contexto do "Prefácio" como uma espécie de ponto de chegada do método interpretativo. Tal importância deve-se a dois motivos em especial, a saber, (1) enquanto categoria histórica, a Origem é o que torna as idéias capazes de refletir a totalidade, e dessa maneira representar a verdade dos objetos; e (2) é ainda uma categoria estrutural responsável por fornecer o conteúdo e a configuração das idéias. Tornemos isso mais palpável.

Enquanto categoria histórica a Origem se distingue claramente da gênese, posto que não pode ser compreendida como o instante em que um objeto passa da inexistência à existência, mas como "algo que emerge do vir-a-ser e da extinção"23. A Origem é uma espécie de cristalização do momento histórico da gênese que interrompe o curso da história e absorve uma dada configuração (Sprung, salto; Ursprung, salto originário, primevo. Aqui como salto para fora da cronologia histórica, do fluxo e do devir). Podemos conceber a Origem como uma categoria que absorve e mimetiza essa dada configuração histórica assim como "o recém-nascido pode ser concebido (...) em um estado de perfeita adequação à configuração atual do cosmo."24

Ao mesmo tempo e, em função de ser a origem uma categoria histórica, é ela, igualmente, uma categoria estrutural do fenômeno originado. E isso porque a 
momentânea interrupção do fluxo do vir-a-ser pelo instante do "salto originário" é o movimento constituinte das idéias. Elas são geradas juntamente com o fenômeno, e em conformidade com o teor histórico determinado pela Origem. Entretanto, por ser de natureza distinta do fenômeno, as idéias surgem não como efetividade espontânea, mas como potências a ser atualizadas pelo fenômeno, no decurso de sua história. Depois de originadas, as idéias permanecem em um estado de latência, como uma espécie de objetivo cuja realização é o propósito mesmo do objeto. Por essa razão, "em cada fenômeno de origem se determina a forma com a qual uma idéia se confronta com o mundo histórico até que ela atinja a plenitude na totalidade da história." ${ }^{25}$

A partir dos elementos acima expostos podemos concluir que todo objetivo almejado no instante histórico, toda meta a partir da qual o objeto se origina é o que permanece como uma promessa de realização interna à sua estrutura. Essa meta é originária, e portanto incorruptível. "Origem é o alvo": o significado dessa enigmática frase de Karl Kraus pode ser agora entendido: o objeto é definido em termos de estrutura - e, assim, simultaneamente em termos de história - pelos alvos almejados em seu instante originário. Todo objeto tende a um fim, que é a atualização das metas estabelecidas estruturalmente pela configuração histórica que o produziu. Com outras palavras, todo objeto tende à atualização de sua Origem.

\section{“Quanto tempo/ vão durar as obras? Vão durar/ Enquanto não estiverem prontas" (B. Brecht, "De como construir obras duradouras") $)^{26}$}

É por sua característica de categoria estrutural, no entanto, que a Origem aparece como elemento determinante na reflexão de Benjamin sobre a história. É preciso, para tanto, compreender tanto seu caráter indestrutível quanto seu caráter de totalidade como traços distintivos.

O que é original é indestrutível porque está para além da transitoriedade e da corrupção. É atemporal, porque no instante em que suas idéias absorvem um momento histórico específico e a partir disso projetam o percurso histórico ideal de seu objeto, o original encerra em sua estrutura tanto a pré-história quanto a pós-história do objeto dado. Enquanto pré-história, o originário mostra-se como restauração do passado; enquanto pós-história, mostra-se como incompletude, inacabamento. "A dinâmica da origem não se esgota na restauração de um estádio primeiro, quer que tenha realmente existido ou que seja somente uma projeção mítica no passado; porque também é 
inacabamento e abertura à história, surgimento histórico privilegiado o Ursprung não é simplesmente restauração do idêntico esquecido, mas igualmente, de maneira inseparável, emergência do diferente. ${ }^{.27}$ A possibilidade da diferença e da resignificação de um passado esquecido

A noção de Origem é particularmente importante para a reflexão acerca da história porque permite apreender o "tempo histórico em termos de intensidade e não de cronologia". ${ }^{28}$ Essa apreensão intensiva do tempo no objeto transforma-o em uma totalidade, em uma "imagem abreviada do mundo". ${ }^{29}$ Ao mesmo tempo, o retira da causalidade histórica linear, na qual o significado de um determinado fenômeno é compreendido somente enquanto este estabelece conexões lógicas com os fatos anteriores e posteriores. O objeto é, assim, transportado para uma outra espécie de temporalidade. Esse novo âmbito é o espaço não do tempo homogêneo e vazio, encadeado numa cronologia pré-estabelecida, mas de um tempo que é pura significação, que se desprende das amarras da sucessão dos fatos e estabelece para si um significado que lhe é imanente. Os objetos históricos assim isolados "são apresentados na sua unicidade e excentricidade como as peças de um museu". ${ }^{30}$

O movimento de constituição da Origem, i.e., interrupção cronológica e cristalização da configuração histórica, é o que garante a possibilidade de reabilitação dessa nova ordem interpretativa do real. Mas ela só fornece essa dimensão de ressignificação porque é também incompletude, e não mera arcaicidade, mero retorno a um passado esquecido:

Ela é ao mesmo tempo indício da totalidade e marca notória de sua falta; nesse sentido ela remete, sim, a uma temporalidade inicial e resplandecente, a da promessa e do possível que surgem na história. Mas nada garante nem o final feliz da história nem da redenção do passado. ${ }^{31}$

No momento em que a análise de um fenômeno fá-lo aparecer com tanta essencialidade que ele se revela como Origem, nos é dada a possibilidade de resgatar as "promessas" recalcadas e não realizadas de seu momento originário e, a partir dessa quebra da estrutura sucessiva da história, atribuir um novo significado não apenas ao fenômeno, mas a toda a realidade.

Quando o pensamento pára, bruscamente, numa configuração saturada de tensões, ele lhes comunica um choque, através do 
qual essa configuração se cristaliza enquanto mônada. Nessa estrutura, ele reconhece o sinal de uma imobilização messiânica dos acontecimentos, ou, dito de outro modo, de uma oportunidade revolucionária de lutar por um passado oprimido. ${ }^{32}$

A verdadeira revolução, para Benjamin, é aquela que volta ao passado para restituir as promessas soterradas pelo "amontoado de ruínas", ${ }^{33}$ trazendo à tona os anseios e as esperanças uma vez instigados pelos oprimidos, pelos que foram derrotados. Nisso consiste a "frágil força messiânica para a qual o passado dirige um apelo". 34

Somente na história, portanto, pode o conceito de Origem ser compreendido, pois a "Origem seria, por assim dizer, uma idéia que só pode se realizar, verdadeiramente (e eu acrescentaria, essencialmente), na história". ${ }^{35}$ Uma vez dada essa conexão, evidente se torna que a compreensão desse conceito central - Ursprung - é o que traz à superfície a relação estruturante e necessária entre a reflexão metódicoepistemológica e a reflexão histórica. E, assim, "a exigência de rememoração do passado não implica simplesmente a restauração do passado, mas também uma transformação do presente tal que, se o passado perdido aí for reencontrado, ele não fique o mesmo, mas seja, ele também, retomado e transformado". ${ }^{36}$

\begin{abstract}
The present paper intends to analyse the interpretative method proposed by Walter Benjamin in the preface to The origin of German tragic drama from the perspective of the concept of Origin (Ursprung) and its paramount importance for the comprehension of the reflection on history, present in the later text entitled "Thesis on the concept of history". The connection between the work on the seventeenth century tragic drama and the study on history consists of the clarification of the concept of Origin as a mainly structural category, to the detriment of the reading that comprehends it from a genetical point of view, as a merely historical and "archaicising" category.
\end{abstract}

Keywords: Origin, interpretative method, history

\title{
Referências Bibliográficas
}


BENJAMIN, Walter. Origem do drama barroco alemão. Trad. de Sérgio Paulo Rouanet, São Paulo: Editora Brasiliense, 1985, 277p. [Coleção Elogio da Filosofia; coordenação de Marilena Chauí]

BENJAMIN, Walter. Origem do drama trágico alemão. Trad. de João Barrento, Lisboa: Assírio \& Alvin, 2004, 363p.

BENJAMIN, Walter. Imagens de Pensamento. In: BENJAMIN, Walter. Rua de mão única. Trad. de Rubens Rodrigues Torres Filho e José Carlos Barbosa, 5. ed., São Paulo: Editora Brasiliense, 2000, 278p. [Obras Escolhidas, v. II]

BENJAMIN, Walter. The task of the translator. In: BENJAMIN, Walter. Selected Writings - v.1: 1913-1926. Editado por Marcus Bullock e Michael W. Jennings, 6. ed., Cambridge, Massachusetts, EUA: Harvard University Press, 2004, 520p.

BENJAMIN, Walter. On the mimetic faculty. In: BENJAMIN, Walter. Reflections: Essays, Aphorisms, Autobiographical writings. Editado por Peter Demetz. Trad. de Edmund Jephcott. Nova York: Editora Schocken Books, 1986, 348p.

BENJAMIN, Walter. Teses sobre o conceito de história. In: BENJAMIN, Walter. Magia e técnica, arte e política. Trad. de Jeanne Marie Gagnebin e Sérgio Paulo Rouanet, 10. ed., São Paulo: Ed. Brasiliense, 1996, 254p. [Obras Escolhidas, v. I] BRECHT, Bertolt. Poems. Part II: 1929-1933, Londres, Eyre Methuen, 1976, p. 193. BUCK-MORSS, Susan. Dialética do Olhar: Walter Benjamin e o Projeto das Passagens. Trad. de Ana Luiza Andrade, Belo Horizonte: Editora UFMG, 2002, 566p. DESCARTES. Meditações ( $2^{a}$ Meditação). Trad. de Jacó Guinsburg e Bento Prado Júnior. São Paulo: Editora Nova Cultural, 1996. [Coleção Os Pensadores]

GAGNEBIN, Jeanne Marie. História e Narração em Walter Benjamin. 2. ed., São Paulo: Editora Perspectiva, 2004, 114p.

MATOS, Olgária. O Iluminismo visionário: Benjamin leitor de Descartes e Kant. São Paulo: Editora Brasiliense, 1993, 184p.

\section{Notas}


${ }^{1}$ BENJAMIN. Imagens de Pensamento, p. 239.

${ }^{2}$ BENJAMIN. Origem do drama barroco alemão.

${ }^{3}$ BENJAMIN. Origem do drama barroco alemão, p. 50.

${ }^{4}$ MATOS. O Iluminismo visionário, p. 10.

${ }^{5}$ BENJAMIN. Origem do drama barroco alemão, p. 50.

${ }^{6}$ BENJAMIN. Origem do drama barroco alemão, p 50.

${ }^{7}$ BENJAMIN. Origem do drama barroco alemão, p. 50.

${ }^{8}$ MATOS. O Iluminismo visionário, p. 11.

${ }^{9}$ BENJAMIN. The task of the translator, p. 13

${ }^{10}$ BENJAMIN. Origem do drama barroco alemão, p. 53.

${ }^{11}$ Conceito tirado de: MACH, Ernst. The economy of science. In: NEWMAN, James R. (Org.). The World of Mathematics. vol. III, New York: Simon \& Schuster, 1988, p. 1759-1767.

${ }^{12}$ GAGNEBIN. História e Narração em Walter Benjamin, p. 11.

${ }^{13}$ BENJAMIN. Origem do drama barroco alemão, p. 54.

${ }^{14}$ BUCK-MORSS. Dialética do Olhar, p. 46.

${ }^{15}$ BUCK-MORSS. Dialética do Olhar, p. 46.

${ }^{16}$ BENJAMIN. Origem do drama barroco alemão, p. 52.

${ }^{17}$ MATOS. O Iluminismo visionário, p. 11.

${ }^{18}$ Exemplo de Descartes em: DESCARTES. Meditações, p.272.

${ }^{19}$ BENJAMIN. Origem do drama barroco alemão, p. 58.

${ }^{20}$ BENJAMIN. Origem do drama barroco alemão, p. 51.

${ }^{21}$ BENJAMIN. Origem do drama barroco alemão, p. 56.

${ }^{22}$ Karl Kraus, Palavras em verso. Apud: BENJAMIN. Teses sobre o conceito de história, p. 229.

${ }^{23}$ BENJAMIN. Origem do drama barroco alemão, p. 68.

${ }^{24}$ BENJAMIN. On the mimetic faculty, p. 334.

${ }^{25}$ BENJAMIN. Origem do drama barroco alemão, p. 68.

${ }^{26}$ BRECHT. Poems. Part II: 1929-1933, p. 193.

${ }^{27}$ GAGNEBIN, História e Narração em Walter Benjamin, p. 18.

${ }^{28}$ GAGNEBIN. História e Narração em Walter Benjamin, p. 8.

${ }^{29}$ BENJAMIN. Origem do drama barroco alemão, p. 70.

${ }^{30}$ GAGNEBIN. História e Narração em Walter Benjamin, p. 10.

${ }^{31}$ GAGNEBIN. História e Narração em Walter Benjamin, p. 14.

${ }^{32}$ BENJAMIN. Teses sobre o conceito de história, tese 17, p. 231.

${ }^{33}$ BENJAMIN. Teses sobre o conceito de história, tese 9, p 226.

${ }^{34}$ BENJAMIN. Teses sobre o conceito de história, tese 2, p. 223.

${ }^{35}$ GAGNEBIN. História e Narração em Walter Benjamin, p.15.

${ }^{36}$ GAGNEBIN. História e Narração em Walter Benjamin, p. 16. 